\title{
Wocovat The influence of peripheral intravenous catheterization on the sleep quality of patients
}

Murayama R 1,2, Abe M 1,2, Takahashi T 2,3, Kanno C 4 , Sanada H 2, 4

1 Department of Advanced Nursing Technology, Graduate School of Medicine, The University of Tokyo, Japan,

2 Global Nursing Research Center, Graduate School of Medicine, The University of Tokyo, Japan,
3 Department of Life Support Technology (Molten), Graduate School of Medicine, The University of Tokyo, Japan

4 Department of Gerontological Nursing/Wound Care Management, Graduate School of Medicine, The University of Tokyo, Japan

\section{Introduction:}

- Peripheral intravenous catheter (PIV) placement is the most common medical treatment method for inpatients. (Carr $P, 2017$ )

PIV placement is an invasive method and uncomfortable experience for patients.

- Catheterization may affect sleep, because patients having a catheter will be worried about the catheter and wake up. (Kobayashi K, 2017)

- However, there have been no studies examining the relationship between PIV placement and sleep quality.

\section{Method:}

- Design: Observational study

- Study setting: Ophthalmic ward of the University of Tokyo Hospital

- Participants: Inpatients who have a planned surgery on the following day. 'Catheterization group' - patients who were administered a PIV with heparin $(100 \mathrm{U} / \mathrm{ml})$ in preparation for a surgery.

'Non-catheterization group' - patients who were not catheterized.

Exclusion criteria: Patients under 20 years old

Sleep parameters:

1) 'Nemuri SCAN' (PARAMOUNT BED CO., LTD. Tokyo, Japan)

2) Subjective sleep quality questionnaires,

The Oguri-Shirakawa-Azumi sleep inventory, MA version (OSA-MA)

Other questions (original)

$$
\text { How was your sleep last night? }
$$

Did you change positions as usual?

How many times did you leave your bed last night?

(Catheterization - Were you able to find a comfortable sleeping position? group only)
$\rightarrow$ If so, what was the reason? (pain, anxiety, itchy, and so on)

This study was approved by the Research Ethics Committee of the Graduate School of Medicine at the University of Tokyo (No.11670).

Table 1.

Characteristics of the catheterization group and non-catheterization group

\begin{tabular}{|c|c|c|c|}
\hline Age [years] & Catheterization $(n=53)$ & Non-catheterization $(n=55)$ & p-value \\
\hline Sex [male] & $72.2 \pm 11.1$ & $70.9 \pm 13.1$ & 0.575 \\
\hline Body Mass Index $\left[\mathrm{kg} / \mathrm{m}^{2}\right.$ ] & $27(50.9)$ & $30(54.5)$ & 0.428 \\
\hline Experience of surgery & $22.8 \pm 3.2$ & $23.2 \pm 4.6$ & 0.547 \\
\hline Taking sleep aid & $43(81.1)$ & $42(76.4)$ & 0.356 \\
\hline PSQI-J ${ }^{1)}$ & $7(13.2)$ & $3(6.0)$ & 0.184 \\
\hline
\end{tabular}

$\mathrm{N}=108$, Mean $\pm \mathrm{SD}$ or $\mathrm{n}(\%)$

1) PSQI-J [0-21]: the Pittsburgh Sleep Quality Index, Japanese Version: The measure consists of 19

individual items, creating 7 components that produce one global score. High score is judged as

sleeping disorder. The cut-off point is 5.5 .

Table 2.

Peripheral intravenous catheterization and sleep parameters by Nemuri SCAN

\begin{tabular}{|c|c|c|c|}
\hline & Catheterization ( $n=53$ ) & $\begin{array}{c}\text { Non-catheterization } \\
(\mathrm{n}=55)\end{array}$ & p-value \\
\hline Total sleep time (min) & $473.4(72.4)$ & $468.1(62.1)$ & 0.688 \\
\hline Time in bed (min) & 558.6 (49.9) & $546.9(54.5)$ & 0.248 \\
\hline Sleep latency (min) & $14.3(9.0)$ & $13.8(10.3)$ & 0.766 \\
\hline Sleep efficiency (\%) & $84.6(9.7)$ & 85.6 (7.9) & 0.542 \\
\hline Waking after sleep onset (min) & $67.1(46.9)$ & $62.8(42.8)$ & 0.623 \\
\hline Out-of-bed (times) & $2.5(1.8)$ & $2.1(2.0)$ & 0.266 \\
\hline Activity score ${ }^{1)}$ [count/min] & $42.9(18.4)$ & $40.0(18.0)$ & 0.422 \\
\hline
\end{tabular}

$\mathrm{N}=108$, Mean $\pm \mathrm{SD}$ or $\mathrm{n}(\%)$

1) Activity score: the intensity and frequency of large body movements (excluding smaller movement, such

as breathing and heartbeat)

Table 3. Peripheral intravenous catheterization and subjective sleep quality

\begin{tabular}{|c|c|c|c|}
\hline & Catheterization ( $n=53$ ) & $\begin{array}{c}\text { Non-catheterization } \\
(\mathrm{n}=55)\end{array}$ & p-value \\
\hline Sleepiness on rising ( 4 items) & $47.7(10.0)$ & $49.1(8.9)$ & 0.426 \\
\hline $\begin{array}{l}\text { Initiation and maintenance of } \\
\text { sleep ( } 5 \text { items) }\end{array}$ & $40.0(10.5)$ & $39.1(11.7)$ & 0.666 \\
\hline Frequent dreaming ( 2 items) & $51.0(10.3)$ & 49.9 (11.9) & 0.622 \\
\hline Feeling refreshed ( 3 items) & $48.4(9.1)$ & $47.7(9.4)$ & 0.698 \\
\hline $\begin{array}{l}\text { Sleep length ( } 2 \text { items) } \\
\quad N=108 \text { Mean }+S D \text { or } n(\%)\end{array}$ & $47.4(12.1)$ & $48.0(10.5)$ & 0.764 \\
\hline
\end{tabular}

Table 4. The relationship between experience of pain associated with movement and sleep parameters by Nemuri SCAN among catheterization group

\begin{tabular}{|l|c|c|c|}
\hline & Yes $(\mathbf{n = 1 2})$ & No $(\mathbf{n = 4 0})$ & p-value \\
\hline Total sleep time (min) & $479.9(68.4)$ & $471.1(75.2)$ & 0.716 \\
\hline Time in bed (min) & $562.7(48.9)$ & $557.1(51.3)$ & 0.739 \\
\hline Sleep latency (min) & $16.5(8.7)$ & $13.6(9.2)$ & 0.343 \\
\hline Sleep efficiency (\%) & $85.0(7.5)$ & $84.4(10.4)$ & 0.858 \\
\hline Waking after sleep onset (min) & $65.3(33.5)$ & $67.9(51.0)$ & 0.866 \\
\hline Out-of-bed (times) & $2.9(2.0)$ & $2.4(1.7)$ & 0.382 \\
\hline Activity score [count/min] & $39.5(9.1)$ & $43.6(20.5)$ & 0.514 \\
\hline Fragmentation index (\%)* & $45.1(7.4)$ & $35.7(10.0)$ & 0.004 \\
\hline
\end{tabular}

$\mathrm{N}=53$ : catheterization group, Missing data $=1$

*Fragmentation Index : the percentage of phases of 1 min immobility vs. the whole periods of immobility

Table 5. The relationship between experience of pain associated with movement and subjective sleep quality among catheterization group

\begin{tabular}{|l|c|c|c|}
\hline & Yes (n=12) & No (n=40) & p-value \\
\hline Sleepiness on rising (4 items) & $44.5(9.8)$ & $48.5(10.1)$ & 0.232 \\
\hline $\begin{array}{l}\text { Initiation and maintenance of sleep } \\
\text { (5 items) }\end{array}$ & $32.8(12.0)$ & $42.0(9.3)$ & 0.007 \\
\hline Frequent dreaming (2 items) & $47.6(13.5)$ & $51.8(9.2)$ & 0.226 \\
\hline Feeling refreshed (3 items) & $42.1(8.7)$ & $50.2(8.6)$ & 0.007 \\
\hline Sleep length (2 items) & $40.8(10.6)$ & $49.1(12.0)$ & 0.036 \\
\hline
\end{tabular}

$\mathrm{N}=53$ : catheterization group, Missing data $=1$

Aims: sleep quality, such as sleep parameters and subjective sleep quality.

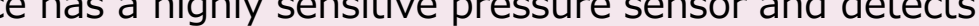

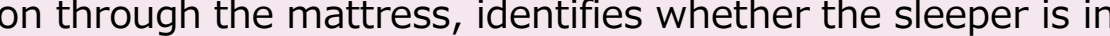
scoring sleep/wake.

This score reflects the intensity and frequency of large body and heartbeat.

Scoring of sleep/wake states was done using the Cole-Kripke

algorithm (Cole et al, 1992). The device can calculate TST: tota

after sleep onset, and Awakenings.

The Oguri-Shirakawa-Azumi sleep inventory, MA version (OSA-MA)

The OSA-MA edition was a short form, targeting middle-aged and elderly people, it 列

1) sleepiness on rising (4 items)

4) feeling refreshing ( 2 items)

5) sleep length ( 2 items)

Scores are standardized to evaluate sleep quality and high scores are judged as good sleep quality.

(Oguri M et al., 1985)

\section{Results:}

catheterization group' were 53 and 55, respectively. (Table 1)

There were no significant differences in sleep parameters or subjective (Table 2,3)

The most widely given reason was 'pain associated with movement' $(63.2 \%)$.

pain associated with movement, Fragmentation Index was higher and three of the five subjective sleep quality factors measured by OSA-MA were lower than those of the other participants.

\section{Discussion \& Conclusion:}

This study found that PIV placement influenced the subjective sleep quality of patients who experienced pain associated with movement, due to stimulus from the catheter, even though it was not related to sleep parameters by body vibrometer. Continued development of the catheter and catheter fixation method are required for reducing pain and improving sleep quality.

\footnotetext{
COI: This is a joint research program with PARAMOUNT BED CO., LTD. (Tokyo, Japan) and was conducted under its sponsorship.
} 